\title{
A Aplicabilidade do Diaminofluoreto de Prata em Criancas de 4 a 10 anos de Idade na Clínica de Odontopediatria da Universidade Federal do Espírito Santo, Brasil
}

\section{The Applicability of the Silver Diamine Fluoride in Children from 4 to 10 Years Old in the Odontopediatrics Clinic in the Federal University of the Espírito Santo, Brazil}

\author{
Lorrayne Belotti ${ }^{\mathrm{a} *}$; Lilian Sarmento Citty ${ }^{\mathrm{ab}}$; Ana Maria Martins Gomes ${ }^{\mathrm{b}}$ \\ âniversidade Federal do Espírito Santo, Programa de Pós-Graduação Stricto Sensu em Saúde Coletiva. Vitória, ES. \\ ${ }^{b}$ Universidade Cruzeiro do Sul, Programa de Pós-Graduação Stricto Sensu em Odontologia. \\ *E-mail: lorraynebelotti@gmail.com \\ Recebido em: 27/04/2015; Aceito em: 20/10/2015
}

\begin{abstract}
Resumo
As manifestações da doença cárie é uma condição crítica em crianças, sendo preconizada para a prevenção e o tratamento a utilização de compostos fluoretados. Neste contexto, o Diaminofluoreto de Prata (DFP) é um composto que se destaca por suas propriedades preventivas e anti-cariogênicas e por sua ação bacteriostática, remineralizante e dessensibilizante. O objetivo deste estudo foi avaliar: a utilização do DFP através da sua ação cariostática na paralização e remineralização da lesão cariosa; a aceitação dos pais ao tratamento proposto; bem como a verificação da sua aplicabilidade, na percepção dos alunos de graduação. Para este fim foi aplicado o Cariestop ${ }^{\circledR} 12 \%$ (Maquira) em 14 crianças, com idades de 4 a 10 anos, com lesões cariosas em esmalte de molares decíduos, a cada semana, durante três semanas consecutivas. Foram utilizados dois questionários, um aos responsáveis e outro aos alunos de odontologia, para verificação da aceitação e aplicabilidade do DFP. Observou-se paralização e remineralização da lesão cariosa em todos os elementos aplicados e aceitação inicial dos pais de $89 \%$ ao tratamento; $64,3 \%$ dos pais perceberam mudança de cor nos elementos, e $100 \%$ acreditaram que essa mudança não irá interferir negativamente na estética da criança. Todos os alunos que participaram da pesquisa consideraram a técnica de fácil aplicabilidade e $63,9 \%$ determinaram ser bom o comportamento da criança durante a aplicação. Conclui-se que a aplicação do DFP apresentou-se clinicamente efetiva na paralisação e remineralização das lesões cariosas em esmalte, tendo uma boa aceitação e podendo ser utilizada como um recurso de mínima intervenção em odontopediatria.
\end{abstract}

Palavras-chave: Cárie Dentária. Cariostáticos. Assistência Odontológica. Odontopediatria.

\begin{abstract}
The manifestations of dental caries is still a critical condition in children, and it was prescribed for the prevention and treatment the usage of fluoride compounds. In this context, the silver diamine fluoride (SDF) is a compound that stands out for its preventive properties and anti-cariogenic and its bactericidal, bacteriostatic, remineralizing and desensitizing. The aim of this study was to evaluate the use of SDF through their cariostatic effect on paralysis and remineralization of caries lesions; acceptance of parents to the proposed treatment, as well as verification of its applicability, as perceived by students in clinical dentistry. To this purpose we applied the Cariestop ${ }^{\circledR} 12 \%($ Maquira) in 14 children aged from 4 to10 years old with carious lesions in enamel of deciduous molars. The application was given every week for three consecutive weeks. Two questionnaires were used, one for the parents and the other for students of dentistry, for verification of the acceptance and applicability of SDF. It was observed paralysis and remineralization of caries lesions in all elements applied and initial acceptance of the parents of $89 \%$ of the treatment, whereas $64.3 \%$ of parents perceived color change in the elements, and $100 \%$ believed that this change does not will negatively affect the aesthetics of the child. All students who participated in the survey considered the technique easy to apply and $63.9 \%$ determined that child behavior during application was good. Concluding that the application of SDF in children were clinically effective in paralysis and remineralization of carious lesions in enamel, having wide acceptance and can be used as a resource of minimal intervention dentistry.
\end{abstract}

Keywords: Dental Caries. Cariostatic Agents. Dental Care. Pediatric Dentistry.

\section{Introdução}

A cárie dentária produz desmineralização das estruturas mineralizadas dos dentes sendo considerada uma doença de caráter multifatorial ${ }^{1}$. Com essa definição, por sua complexidade, torna-se muito difícil compreendê-la completamente ${ }^{2}$. Por isso, seria anacrônico continuar a pensar na doença cárie como apenas uma interação dos fatores primários, tais como microbiota, hospedeiro e substrato. Visto que aspectos relativos a condições socioeconômicas da população, como escolaridade, renda, classe social, comportamento e atitudes, devem ser considerados. Logo, é coerente observar que a sua prevalência está diretamente ligada e influenciada cada vez mais pelo contexto social no qual ela aparece ${ }^{3}$.

De acordo com os dados conclusivos do Projeto SB Brasil 2002/2003, mesmo com o crescimento das práticas preventivas, a prevalência de cárie em crianças aos cinco anos de idade foi de $60 \%$. Para as crianças de 18 a 36 meses, em média $27 \%$ desses indivíduos apresentaram ao menos um elemento decíduo com experiência de cárie 4 .

As manifestações da doença cárie, principalmente em crianças ainda é uma condição crítica; visto que o tratamento odontológico nesses indivíduos representa um quadro extremamente difícil, por se tratar de pacientes imaturos e nem sempre receptivos à terapia proposta ${ }^{5}$. Diante disto, quando crianças são acometidas por cárie, seja devido à falta 
de prevenção ou impossibilidade de acesso aos serviços, torna-se importante o uso de agentes que controlem a progressão da lesão, na espera do tratamento restaurador ou mesmo na adaptação da criança aos novos hábitos higiênicos e alimentares ${ }^{6}$.

Para tal situação, preconiza-se primeiramente a adequação do meio bucal e condicionamento psicológico, até que a criança esteja preparada para receber o tratamento restaurador convencional, de forma mais efetiva e satisfatória ${ }^{7}$. Neste contexto, para Santos-Júnior, Souza e Rosenblatt ${ }^{3}$ um dos agentes de controle de cárie que se mostra bem eficaz é o Diaminofluoreto de Prata (DFP), considerando que o seu uso poderia aumentar potencialmente o acesso aos cuidados em saúde, melhorar a saúde oral e finalmente reduzir a necessidade de atendimentos de urgência.

Porém, o DFP ainda é pouco utilizado no serviço público, entretanto, seu mecanismo de ação e os estudos publicados que demonstram sua eficácia clínica, comprovam que essa pode ser uma substância de escolha nesse serviço ${ }^{8,9}$. A sua utilização pode ser feita na fase aguda da doença em pacientes não colaboradores, especiais e de acordo com as condições de trabalho em determinada situações, como na falta de material. Pois se trata de um material de baixo custo, indolor, seguro, de fácil aplicação, dispensa a utilização de anestesia e brocas, não destrói a estrutura do dente e tem alta eficácia ${ }^{3,5,10 .}$

Guedes-Pinto $^{11}$, em 2009, afirmou que a utilização do diaminofluoreto de prata é uma opção não invasiva perfeitamente exequível para o controle de lesões cavitadas quando da impossibilidade de abordagem convencional ou em ações coletivas. Ainda, as soluções cariostáticas à base de DFP são alternativas na prevenção de lesões em superfícies oclusais em substituição aos selantes oclusais. Desta forma, a aplicação do DFP pode ser efetuada tanto em dentes decíduos como em permanentes, geralmente em pacientes que tenham um elevado risco de cárie, como em crianças propensas à cárie severa ou pacientes submetidos à radiação de cabeça e pescoço 9 .

Ainda no que concerne a sua utilização no serviço público, Almeida et al. ${ }^{12}$ após realizar um estudo longitudinal com 120 crianças com objetivo de avaliar os efeitos cariostático e anticariogênico do DFP, concluiu que devido sua eficácia e seu baixo custo, o DFP pode ser aplicado por uma THD treinada, dispensando a infraestrutura de um consultório odontológico, sem que haja comprometimento dos resultados. Surgindo, assim, como tratamento alternativo, principalmente em programas de saúde coletiva.

O Diaminofluoreto de Prata se destaca por suas propriedades anticariogênicas, reduzindo a solubilidade da apatita, enquanto a prata, por sua ação bactericida e bacteriostática $^{5}$. Além disso, apresenta ação preventiva, ação remineralizante e ação dessensibilizante. Com estas propriedades o DFP é capaz de inibir a cárie bem como a sua sintomatologia ${ }^{1}$.
O mecanismo de ação baseia-se na atuação destes dois principais constituintes: o nitrato de prata $\left(\mathrm{AgNO}^{3}\right)$, que tem potente ação de coagulação da proteína, e o fluoreto de sódio $(\mathrm{NaF})$, que na reação com esmalte dentário forma fosfato de cálcio $\left(\mathrm{CaF}^{2}\right)$ e fosfato de prata $\left(\mathrm{AgPO}^{4}\right)$, que ficam precipitados na superfície do dente, agindo como uma resistência contra a cárie dentária ${ }^{6}$. $\mathrm{O} \mathrm{CaF}^{2}$ atua como uma reserva de flúor para neutralização de eventual desequilíbrio no processo DES-RE.

A ação da prata sobre as proteínas garante a ação antibacteriana do diaminofluoreto de prata. A coagulação proteica inativa enzimas do metabolismo bacteriano e reduz a microbiota envolvida no processo carioso, como os Streptococcusmutans, inibindo a aderência e o crescimento bacteriano e, consequentemente, a formação de biofilme dentário ${ }^{13}$.

Existem algumas ressalvas em relação ao caráter antiestético do DFP, visto que a sua utilização torna enegrecidas as áreas afetadas pelo processo carioso, embora seu benefício torna-se mais relevante ${ }^{10}$. No entanto, após a paralização da lesão e redução de microrganismos, a estética pode ser restabelecida, por exemplo, quando houver maiores condições de infraestrutura ${ }^{3}$. Porém, devido sua característica enegrecida, alguns profissionais não costumam indicar ou utilizar esse agente cariostático, receosos de uma possível não aceitação por parte dos pacientes ou seus responsáveis legais ${ }^{5}$.

No que concerne à aceitação dos pais de crianças brasileiras na utilização do DFP sobre dentes decíduos portadores de lesões cariosas, constatou-se que os responsáveis consideraram que a estética não é um fator decisivo no momento da indicação deste agente ${ }^{1}$. Essa afirmação foi comprovada, quando Triches et $a .^{5}$, em pesquisa com o objetivo de avaliar a aceitação estética quanto ao uso do cariostático em crianças atendidas na Clínica de Bebês da Unipar, de Cascavel/PR, concluíram que o DFP foi bem aceito pelos responsáveis, considerando que a estética não é um fator decisivo no momento da indicação do cariostático.

Diante do exposto, avaliar a utilização do DFP como técnica de mínima intervenção na clínica de Odontopediatria é uma ferramenta importante na promoção de saúde bucal. O objetivo deste estudo foi observar clinicamente a efetividade do DFP na paralisação de lesões cariosas após sua utilização, a aceitação dos pais/responsáveis ao tratamento proposto, bem como verificar a aplicabilidade do cariostático por meio da percepção dos alunos que participaram do estudo na Clínica de Odontopediatria da Universidade Federal do Espírito Santo.

\section{Material e Métodos}

Esta pesquisa consiste em um estudo clínico experimental longitudinal em crianças que frequentavam a Clínica de Odontopediatria da Universidade Federal do Espírito Santo, e teve seu início após inscrição na Plataforma Brasil e aprovação do Comitê de Ética em Pesquisa da Universidade 
Federal do Espírito Santo, sob o número 242.841, processo: 12111113.0.0000.5060, datado de 10/4/2013. Aos pais/ responsáveis pelas crianças foi explicado o efeito da aplicação do DFP e o Termo de Consentimento Livre Esclarecido foi assinado por aqueles que concordaram com o seu uso. Crianças maiores de sete anos, que concordaram com o procedimento assinaram o Assentimento Informado.

Como critérios de inclusão para a pesquisa em molares decíduos, as crianças tinham entre 4 e 10 anos de idade, sem doenças sistêmicas e com cárie em esmalte e adotou-se como critérios de exclusão os molares decíduos que apresentavam cárie em dentina ou com envolvimento pulpar. O diagnóstico foi feito por um minucioso exame clínico, sendo utilizado como critério para seleção as lesões de cárie em esmalte nos molares decíduos. Classificadas de acordo com $\operatorname{ICDAS}^{14} \mathrm{em}$ : código 1, como primeira alteração visual no esmalte; código 2, como alteração visual evidente no esmalte; e código 3, como rompimento localizado no esmalte devido a cárie, sem dentina visível (Figura 1 e 2).

Figuras 1. As imagens representam os dentes que foram selecionados para pesquisa. Elemento 55, classificado em código 1 de acordo com ICDAS; elemento 75, classificado como código 2; elemento 75 , classificado como código 3 , respectivamente.

\section{A) Elemento 55 - Código 1}

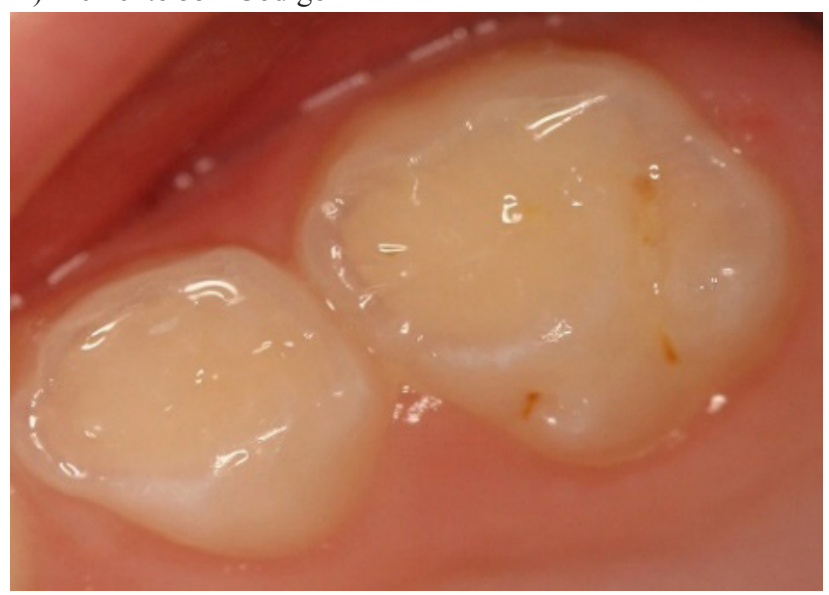

Fonte: Os autores.

B) Elemento 75 - Código 2

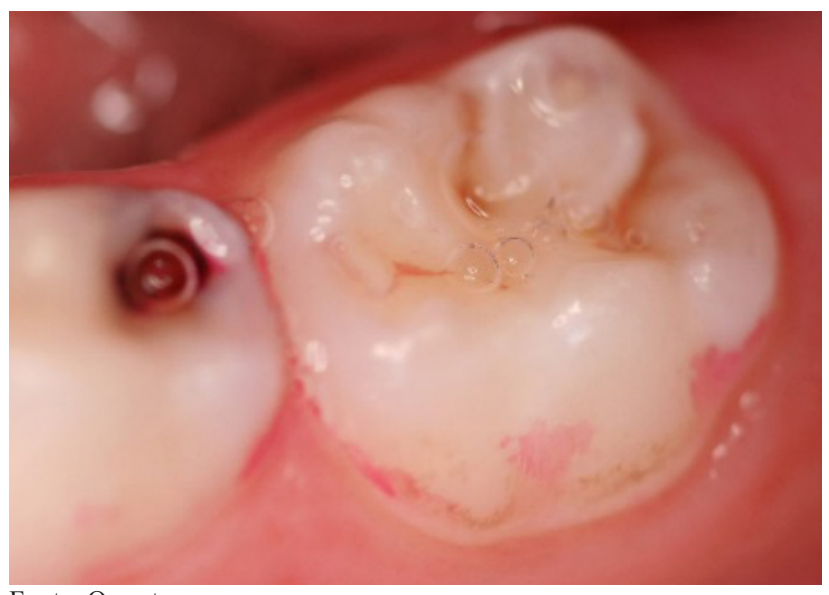

Fonte: Os autores.
C) Elemento 75 - Código 3

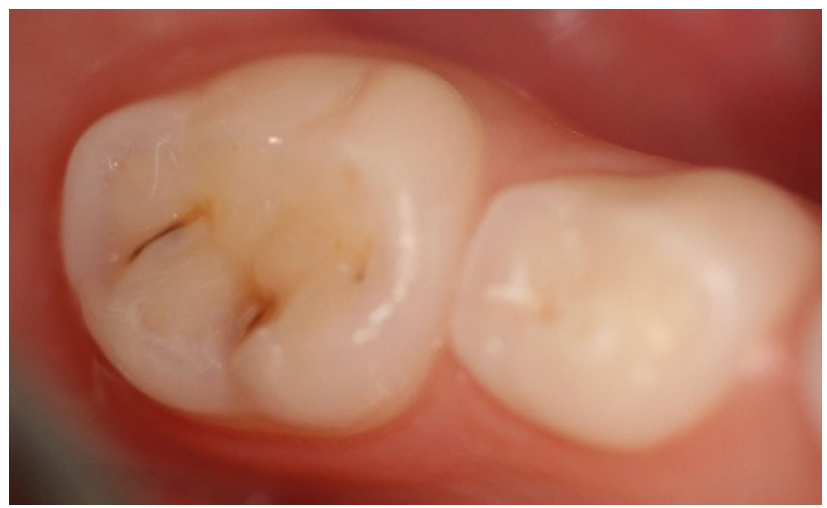

Fonte: Os autores.

O procedimento clínico para este estudo consistiu na aplicação do diaminofluoreto de prata na concentração de 12\% (Cariestop ${ }^{\circledR}$ 12\% MAQUIRA) nos molares decíduos selecionados. O protocolo para o uso do DFP seguiu o recomendado por Santos et al. ${ }^{15}$, em que realizou-se profilaxia prévia, isolamento relativo com roletes de algodão, uso de sugador e secagem com jato de ar. Os tecidos moles adjacentes foram protegidos com vaselina. $\mathrm{O}$ produto foi aplicado com um microbrush por cerca de três minutos e em seguida lavado com jatos de água. A aplicação se deu a cada semana, durante três semanas consecutivas e as crianças foram avaliadas após um mês da última aplicação (Figuras 2).

Figuras 2: Protocolo seguido para aplicação do DFP. (a) Profilaxia prévia (b) Isolamento relativo com algodão e proteção dos tecidos moles com vaselina (c) Aplicação do DFP com microbrush

A)

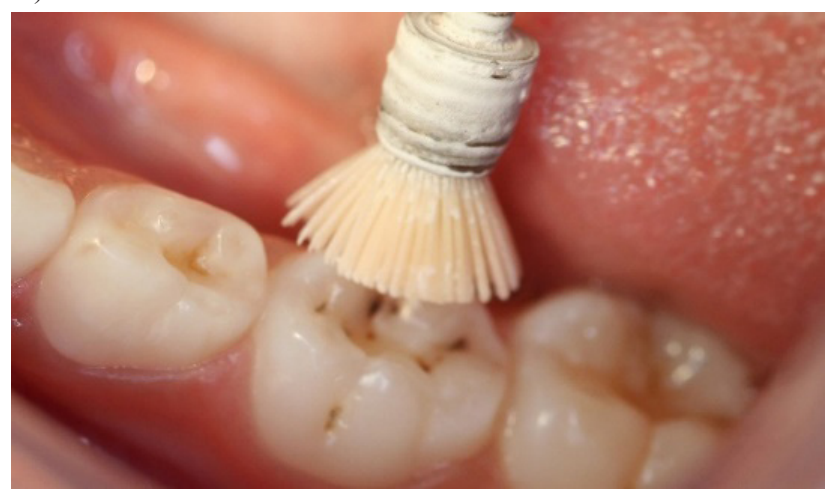

B)

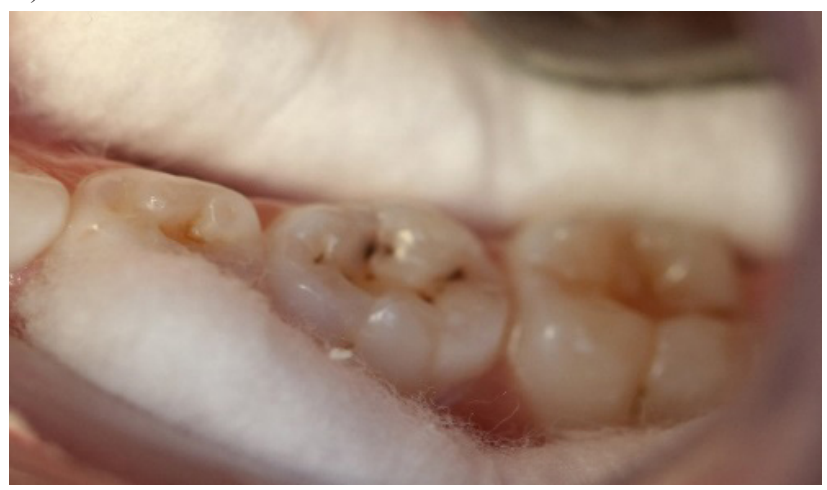


C)

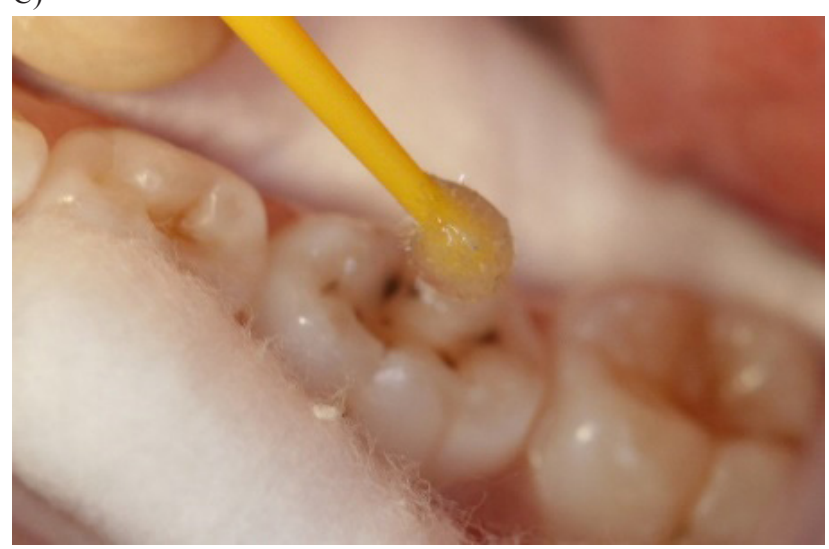

Fonte: Os autores.

Após um mês da última aplicação, os dentes foram avaliados de acordo com os seguintes aspectos:

a) Paralização da lesão cariosa, levando-se em consideração o tamanho da lesão.

b)Remineralização, considerando-se o endurecimento e a coloração da lesão.

Para análises da dinâmica da lesão, as avaliações clínicas foram realizadas com sondas tipo OMS, em ambiente seco e iluminado. Apenas um avaliador realizou todas as observações. Além disso, foram feitas fotografias do antes e depois do tratamento para mensuração do tamanho e análise da cor das lesões.

Para o desenvolvimento deste estudo também foram elaborados dois questionários, aplicados após o término do tratamento, sendo um para os pais e responsáveis das crianças que participaram da pesquisa, constando 3 perguntas de múltipla escolha com o objetivo de avaliar a aceitação estética da utilização do DFP, baseado nos estudos de Triches et $a l .^{5}$. O outro questionário foi destinado ao profissional, aluno de graduação que participou da pesquisa, efetuando o procedimento de aplicação do DFP durante o estudo, para avaliação da aplicabilidade e aceitação do material. Foram elaboradas quatro perguntas relacionadas à técnica de aplicação, ao comportamento da criança em relação a outros procedimentos realizados na clínica de odontopediatria, à utilização do cariostático e aos resultados clínicos após a aplicação.

\section{Resultados e Discussão}

Inicialmente, foram selecionadas 21 crianças que cumpriam os critérios de inclusão determinados para pesquisa. $\mathrm{O}$ número reduzido pode ser explicado pela dificuldade em encontrar lesões de cárie incipientes nas crianças que buscam tratamento odontológico na Universidade Federal do Espírito Santo. Geralmente, as lesões já estavam em estágio avançado, se estendendo à dentina, e assim eram excluídos da amostra. Além disso, sete responsáveis não aderiram ao tratamento proposto quando lhe era explicado o possível efeito estético que o cariostático poderia produzir. E assim, o tratamento se deu de forma convencional.

Portanto, este trabalho foi realizado com 14 crianças de ambos os gêneros, sendo seis meninas e oito meninos com idades entre quatro e 10 anos. Foi aplicado cariostático em 36 dentes (Tabela 1).

Tabela 1: Frequência absoluta e relativa das características dos participantes da pesquisa. Vitória, ES, 2015

\begin{tabular}{ccc}
\hline & $\mathbf{N}$ & $\mathbf{\%}$ \\
\hline Sexo & & \\
Feminino & 6 & $42,8 \%$ \\
Masculino & 8 & $57,2 \%$ \\
Idade & & \\
$4-5$ & 4 & $43,0 \%$ \\
$6-7$ & 6 & $28,5 \%$ \\
$9-10$ & 4 & $28,5 \%$ \\
\hline Total & $\mathbf{1 4}$
\end{tabular}

Fonte: Dados da pesquisa.

Em relação ao aspecto, em todos os elementos dentários em que foi aplicado o cariostático, observou-se paralização da atividade cariosa e remineralização da lesão. Verificando-se que, em todos os casos as lesões apresentaram-se clinicamente enegrecidas, principalmente em sulcos e fissuras oclusais (Figuras 3).

Figuras 3: Comparação entre o aspecto inicial da lesão cariosa e o final após 3 aplicações de DFP no elemento 85

A) Antes

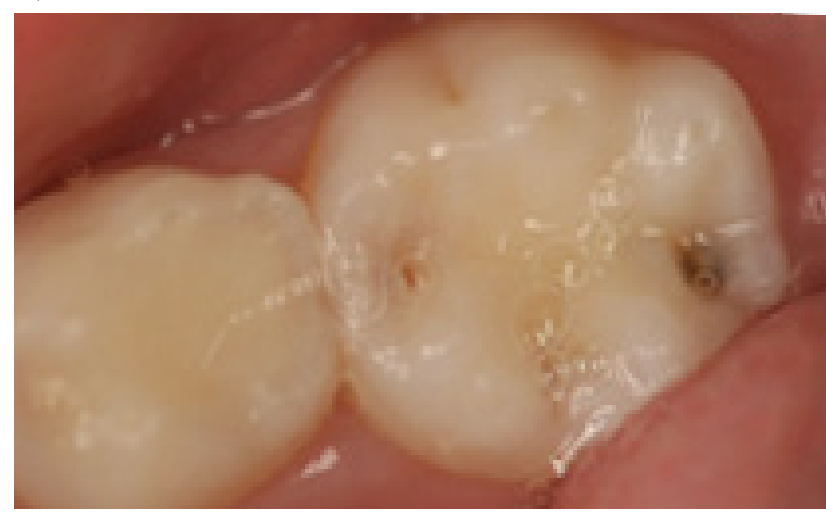

B) Depois

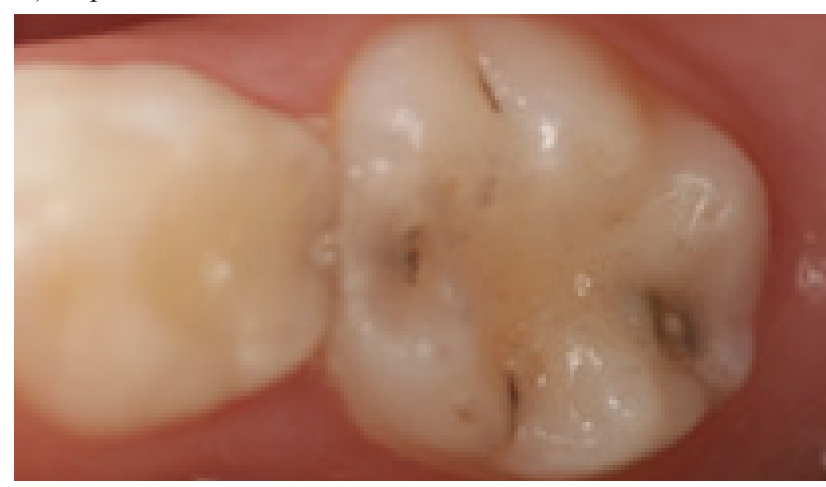

Fonte: Os autores. 
Também foram avaliadas as características clínicas para testar a efetividade do cariostático, segundo Guedes-Pinto ${ }^{11}$. Dessa forma, avaliou-se as características: paralização da lesão cariosa; remineralização no sítio de aplicação; e o aspecto enegrecido do dente após a aplicação (Tabela 2).

Tabela 2: Características avaliadas para testar a efetividade clínica do cariostático, segundo Guedes Pinto ${ }^{11}$. Vitória, ES

\begin{tabular}{lcc}
\hline \multicolumn{1}{c}{ Características } & \multicolumn{2}{c}{ Total de dentes } \\
& Avaliados & $\begin{array}{c}\text { Resposta ao } \\
\text { Tratamento }\end{array}$ \\
\hline Paralisação da lesão & 36 & positiva \\
Remineralização & 36 & positiva \\
Aspecto enegrecido & 36 & positivo \\
\hline
\end{tabular}

Fonte: Dados da pesquisa.

Em relação ao questionário aplicado aos pais e responsáveis pelas crianças do estudo, foi perguntado se, após a utilização do cariostático, perceberam alguma diferença estética nos dentes aplicados. Nesse quesito, 64,3\% responderam que sim, perceberam. Enquanto 28,6\% não notaram nenhuma diferença e 7,1\% não sabiam responder. Para os pais que perceberam a diferença, perguntou-se se ele acreditaria que essa alteração poderia interferir negativamente na estética da criança. Todos responderam que acreditam não haver interferência na estética (Tabela 3).

Tabela 3: Frequência relativa da percepção dos pais quanto à diferença estética após aplicação do cariostático. Vitória, ES.

\begin{tabular}{lccc}
\hline \multicolumn{1}{c}{ Percepção dos Pais } & Sim & Não & Não Sei \\
\hline Notou diferença estética & $64,3 \%$ & $28,6 \%$ & $7,1 \%$ \\
$\begin{array}{l}\text { Essa diferença interfere } \\
\text { negativamente na estética }\end{array}$ & $0 \%$ & $100 \%$ & $0 \%$ \\
\hline Fonte: Dados da pesquisa. & & &
\end{tabular}

Com o objetivo de obter informações sobre a aceitação dos pais e/ou responsáveis ao DFP após conhecer suas vantagens e desvantagens, foi lhes perguntados se aceitariam novamente o tratamento com o cariostático caso fosse necessário. As opções de respostas foram as seguintes: a) Aceitaria prontamente; b) Jamais aceitaria; c) Não aceitaria porque é feio (não é estético); d) Não acho tão feio, mas não aceitaria; e) Acho muito feio (não é estético), mas aceitaria, porque saúde é mais importante que estética; f) Não importa que seja feio, mas que resolva o problema, porque saúde é mais importante que estética. Com estas opções de respostas citadas acima, 78,6\% dos pais desponderam a opção a) e 21,4\% a opção f) (Gráfico 1).
Gráfico 1: Resposta dos pais quando perguntados se aceitariam novamente o tratamento com cariostático. (a) Aceitariam prontamente (f) Não importa que seja feio, mas que resolva o problema, porque saúde é mais importante que estética.

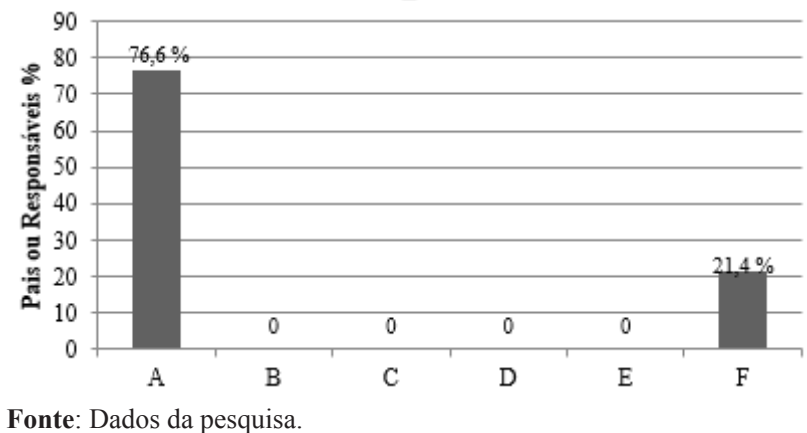

Fonte: Dados da pesquisa.

Quanto aos resultados dos 11 alunos do sétimo período do Curso de Odontologia da UFES que acompanharam a pesquisa de perto, todos consideraram a técnica de utilização do Diaminofluoreto de Prata de fácil aplicabilidade; em relação aos resultados encontrados $9,10 \%$ consideraram muito bom; $63,6 \%$ consideraram bons e 27,3 consideraram regulares. Quando perguntados sobre o comportamento da criança durante a aplicação de DFP comparado com procedimentos invasivos, 63,6\% dos alunos consideraram as crianças com bom comportamento e $36,4 \%$ muito bom durante a aplicação (Tabela 4).

Tabela 4: Frequência relativa da percepção dos alunos quanto à utilização clínica do cariostático. Vitória, ES

\begin{tabular}{lcccc}
\hline $\begin{array}{c}\text { Percepção dos } \\
\text { Alunos }\end{array}$ & $\begin{array}{c}\text { Muito } \\
\text { Bom }\end{array}$ & Bom & Regular & Ruim \\
\hline $\begin{array}{l}\text { Resultados } \\
\text { encontrados }\end{array}$ & $9,1 \%$ & $63,6 \%$ & $27,3 \%$ & $0 \%$ \\
$\begin{array}{l}\text { Comportamento } \\
\text { da criança } \\
\text { durante a } \\
\text { aplicação }\end{array}$ & $36,4 \%$ & $63,6 \%$ & $0 \%$ & $0 \%$ \\
\hline
\end{tabular}

Fonte: Dados da pesquisa.

Em relação à aplicação do DFP na clínica odontológica, $36,7 \%$ dos alunos responderam que sempre utilizariam, 63,6\% responderam que às vezes usariam e não ninguém respondeu que nunca usariam (Gráfico 2).

Este estudo experimental clínico foi realizado em 14 crianças que procuraram a Clínica de Odontopediatria da UFES para atendimento odontológico. O DFP foi aplicado em 36 dentes, todos classificados entre os códigos 1, 2 e 3 de acordo com ICDAS, com o objetivo de avaliar a aplicabilidade e aceitação do material dentro da filosofia de mínima intervenção.

O diaminofluoreto de prata apresenta em sua composição hidróxido de amônia, nitrato de prata, hidróxido de cálcio, ácido fluorídrico e solvente. No Brasil são comercializados nas concentrações de $10 \%, 12 \%, 30 \%$ e $38 \%$, com inúmeras marcas comerciais ${ }^{7}$. Para este estudo foram utilizadas aplicações semanais com DFP numa concentração de $12 \%$ da 
marca Maquira ${ }^{\circledR}$.

As diferentes concentrações do produto determinam a quantidade de aplicações e o intervalo entre elas. Em alguns estudos, as aplicações de diaminofluoreto de prata foram feitas de 3 em 3 meses, com concentração de $12 \%{ }^{12,16}$, em outros de 6 em 6 meses com maiores concentrações ${ }^{17}$. Os resultados obtidos pelos autores que realizaram apenas aplicações trimestrais foram semelhantes, apesar de terem utilizado diferentes concentrações do produto, o que sugere que a redução da concentração não altera as propriedades benéficas do cariostático, o que seria uma vantagem pois uma solução menos concentrada reduziria as chances de irritação pulpar.

Llodra et al. ${ }^{18}$ realizaram um ensaio clínico controlado prospectivo para avaliar a ação do DFP a $38 \%$ na prevenção e paralisação de cárie em dentes decíduos e nos primeiros molares permanentes. A fração preventiva nos dentes decíduos foi de $80 \%$ e nos dentes permanentes de $65 \%$, demonstrando a eficácia da aplicação semestral de solução a 38\% de DFP na paralisação e prevenção de cárie em ambas as dentições.

Considerando a metodologia aplicada, observamos em nossos resultados, após um mês da aplicação do DFP, uma eficácia clínica de $100 \%$ dos casos na paralisação e remineralização das lesões cariosas em esmalte. O DFP age tanto na porção inorgânica quanto na porção orgânica do elemento dentário. Sendo que o fluoreto de sódio age na hidroxiapatita e o nitrato de prata na porção orgânica das proteínas ${ }^{3}$.

A composição básica do cariostático foi desenvolvida com a intenção de associar as ações antibacterianas da prata (coagulação das proteínas e inativação das enzimas bacterianas) e a remineralizadora do flúor ${ }^{19}$. Além das propriedades físicoquímicas, o DFP apresenta ações cariostática, anticariogênica, preventiva, remineralizante e dessensibilizante. Podendo, desta forma, diminuir a sensibilidade dentária ${ }^{1}$.

Com o objetivo de avaliar o efeito inibitório do DFP a $38 \%$ na desmineralização da dentina, May et al. ${ }^{20}$ realizaram um estudo laboratorial no qual compararam a utilização do cariostático 38\% (253,900 ppmAg, 44800 ppmF), com grupos em que utilizaram apenas solução de nitrato e solução de fluoreto de sódio, com as mesmas concentrações do produto DFP, porém isolados. E concluíram que o uso do DFP a $38 \%$ inibiu a desmineralização e preservou a degradação do colágeno, além de ter exercido influência positiva na remineralização dentinária.

Com relação à remineralização das lesões de cárie que confere aos dentes o aspecto enegrecido, de acordo com os autores, o indesejável manchamento encontrado em todos os elementos em que o DFP foi aplicado ocorre de formas distintas, em camadas que envolvem esmalte e dentina ${ }^{3,6}$. Nesta pesquisa o DFP foi aplicado apenas em dentes com lesões cariosas em esmalte, e observou-se clinicamente o escurecimento das respectivas lesões, provavelmente em função do alto poder de pigmentação da prata e impregnação dos seus íons no esmalte.

Sabe-se que por esse caráter antiestético muitos profissionais descartam a utilização do DFP na rotina odontológica, receosos da não aprovação da família perante os resultados encontrados. Entretanto, em relação aos resultados estéticos, estudos já revelaram que, uma vez orientados quanto aos benefícios relacionados ao emprego do DFP, os pais não apresentaram qualquer objeção quanto à sua utilização ${ }^{14,4,1}$. Neste estudo a aceitação inicial dos pais quanto ao tratamento proposto foi de $89 \%$. O que vai de acordo com os estudos de Triches et $a l^{5}$, no qual os autores verificaram que a maioria $(60 \%)$ dos pais não se preocupavam com o resultado antiestético do DFP, desde que resolvesse o problema, por acreditarem que a saúde é mais importante que a estética.

Desta forma, quando os responsáveis foram perguntados se houve percepção de alguma diferença após o uso do cariostático, 64,3\% disseram que sim, perceberam mudanças. Porém, que acreditavam que essa diferença não iria afetar negativamente na estética da criança. Estes achados sugerem a importância de se reavaliar a preocupação quanto à estética relacionada ao uso deste produto, já que o aspecto enegrecido das lesões muitas vezes pode não ser visto como um problema pelos responsáveis. Quando perguntados se aceitariam novamente o tratamento com DFP, 78,6\% dos responsáveis relataram que aceitariam prontamente, enquanto apenas $21,4 \%$ optaram por responder que não se importavam que fosse feio, mas que resolvesse o problema, porque saúde é mais importante que estética.

Além de muitos profissionais descartarem o uso do DFP pelo aspecto enegrecido, consideram o selamento de cavidades cariadas muito mais estético, e que a utilização de verniz com flúor substituiria o uso do cariostático ${ }^{3}$. Porém, Chu et al. ${ }^{8}$ compararam a eficácia do verniz com flúor quando aplicado duas vezes ao ano com o DFP aplicado uma vez por ano. Sua amostra foi composta por 375 crianças entre três e cinco anos de idade, que possuíam dentes cariados. Os resultados do estudo indicam que o DFP foi substancialmente mais eficaz do que o verniz com flúor na capacidade de paralisar e prevenir novas cáries $(96,1 \%$ e $70,3 \%$, respectivamente, para o grupo de DFP, e $21,3 \%$ e $55,7 \%$, respectivamente, para o grupo de verniz com flúor).

Quando consideramos o selamento mais eficaz, há que se pensar que ainda existem comunidades muito carentes em todo o mundo, onde não há dentistas ou consultórios equipados. Assim, o protocolo para uso do DFP, preconizado nesta pesquisa, facilita sua utilização em lugares adversos, principalmente em populações carentes, onde não há muitos meios de intervir. Uma vez que nos consultórios privados, o profissional pode lançar mão de diversos métodos para tratamento, desde o mais simples, até os mais sofisticados. Todavia, em saúde pública, as condições de trabalho são muitas vezes limitadas, tanto pela escassez de profissionais habilitados para o atendimento infantil, como também pela 
restrita possibilidade de opção por materiais de consumo e equipamento ${ }^{21}$.

A utilização do diaminofluoreto de prata, além de ser preconizada por mais da metade dos cursos de especialização em odontopediatria do Brasil ${ }^{22}$, é indicada com convicção e segurança em Saúde Pública, pois o método de aplicação é bastante simples e rápido, o custo do produto é baixo e suas propriedades permitem versatilidade de uso em diversas situações $^{14}$.

Tais situações também podem levantar a questão da mudança de paradigma de selagem ou enchimento de cavidades para a redução da cárie ativa, especialmente quando erros de diagnóstico podem ocorrer mais frequentemente nestas circunstâncias do que em ambientes clínicos tradicionais ${ }^{3}$. Por isso, quando perguntados sobre a facilidade de aplicação do cariostático considerando uma técnica de mínima intervenção, todos os alunos consideraram de fácil aplicabilidade. Pois sabe-se que o DFP além de possuir efeito de redução de microrganismos $^{23}$, é um agente terapêutico extremamente acessível para o uso em Saúde Pública, de fácil aplicação e alto impacto sobre a atividade de cárie ${ }^{19,21}$.

Após a avaliação individual do paciente, baseado na sua necessidade, adotam-se procedimentos de adequação bucal que incluem ações educativas e motivacionais para o controle do biofilme dental ${ }^{1,19}$. Esses procedimentos, além de restabelecer o equilíbrio do meio bucal, auxiliam no condicionamento psicológico da criança que passa a aceitar com maior facilidade o tratamento odontológico que está por vir, visto que muitos não compreendem a necessidade do atendimento odontológico. Nesse aspecto, 63,6\% dos acadêmicos consideraram bom, e 36,4\% consideraram muito bom o comportamento da criança durante a aplicação do DFP, quando comparados a procedimentos invasivos realizados nelas.

Cientes dos benefícios e resultados encontrados com o estudo realizado, $36,4 \%$ dos estudantes responderam que sempre usariam o DFP e $63,6 \%$ disseram que às vezes utilizariam, sendo que nenhum teve uma recusa na utilização do cariostático na clínica, quando foi necessário. Isso nos mostra que, assim como os pais, os profissionais quando esclarecidos sobre os benefícios e a facilidade do uso do DFP, tornam-se dispostos a propor o tratamento aos responsáveis. Principalmente quando a aplicação se dá em lugares com pouca visibilidade estética, em molares, como ocorreu nesta pesquisa. Os que responderam "às vezes", relataram que não utilizariam em regiões anteriores. O que nos leva a inferir que o produto teve uma boa aceitabilidade entre os estudantes, principalmente quando da sua aplicação em dentes posteriores.

\section{Conclusão}

Com base nos resultados encontrados e nas condições em que este trabalho foi realizado foi possível concluir que: a aplicação do DFP em crianças com cárie de esmalte mostrou- se eficaz na paralisação e remineralização das lesões cariosas pela ação antibacteriana da prata e remineralizadora do flúor; os pais e os responsáveis aderiram bem ao tratamento quando os benefícios foram explicados e consideraram que o manchamento dos dentes não interferiu negativamente na estética das crianças; os alunos que participaram do estudo consideraram bons os resultados obtidos com a aplicação do DFP. Podendo ser empregado no condicionamento psicológico da criança, o DFP é uma técnica de mínima intervenção, de fácil aplicabilidade e boa aceitação clínica, podendo por isso ser utilizado na clínica de odontopediatria e na Saúde Pública.

Por fim, tendo em vista o número reduzido da amostra, sugere-se realização de mais pesquisas com o DFP para fomentar ainda mais sua utilização na clínica de odontopediatria.

\section{Referências}

1. Alves TM, Silva CA, Silva NB, Medeiros EB, Valença AMG. Atividade Antimicrobiana de Produtos Fluoretados sobre Bactérias Formadoras do Biofilme Dentário: Estudo in vitro. Pesq Bras Odontoped Clin Integr 2010;9(3);265-9.

2. Lima JEO. Cárie dentária: um novo conceito. Rev Dental Press Ortodon Ortop Facial 2007;12(6):119-30.

3. Santos Júnior VE, Souza PR, Rosenblatt A. Um recurso para paralisar e prevenir cárie em crianças: diamino fluoreto de prata. RFO 2012;17(2);228-33.

4. Brasil. Ministério da Saúde. Projeto SB Brasil 2003. Condições de saúde bucal da população brasileira 2002-2003. Resultados principais. Brasília: MS; 2004.

5. Triches TC, Cordeiro MMR, Souza JGMV, Saltori EK, França BHS. Aceitação dos pais quanto ao uso do diaminofluoreto de prata em crianças de 0 a 3 anos de Cascavel/PR. Pesq Bras Odontoped Clin Integr 2009;9(3);265-9.

6. Ditterich RG, Romanelli MCV. Diamino fluoreto de prata: uma revisão de literatura. UEPG Cienc Biol Saúde 2006;12(2):4552.

7. Castro RD, Ângelo AR, Araújo IM, Torres BOT. A utilização do diaminofluoreto de prata na prevenção e controle da cárie em esmalte dentário. Int J Dent 2009;8(2);98-101.

8. Chu $\mathrm{CH}$, Lo EC, Lin H. Effectiveness of silver diamine fluoride and sodium fluoride varnish in arresting dentin caries in Chinese pre-school children. J Dent Res 2002;81;767-70.

9. Montandon EM, Sperança PA. Estudo comparativo in vitro da atividade antimicrobiana de agentes cariostáticos à base de Diamino Fluoreto de Prata. J Bras Odontopediatr Odontol Bebê 2000;3(16);465-74.

10. Rocha C, Miasato JM, Farinhas J, Schuller AF. Diamino Fluoreto de Prata: uma opção em odontopediatria. J Bras Odontopediatr Odontol Bebê 1999;2(8);296-301.

11. Guedes-Pinto AC. Fundamentos de odontologiaodontopediatria. São Paulo: Livraria Santos; 2009.

12. Almeida ICS, Bijella MFTB, Lima, JEO, Vono AZ, Freitas SFT. Avaliação dos efeitos cariostático e anticariogênico do diaminofluoreto de prata a 12\% (Bioride): estudo longitudinal. Rev Fac Odontol Bauru 1994;2(4);28-30.

13. Craig GG, Powell KR, Price CA. Clinical evaluation of a modified silver fluoride application technique designed to 
facilitate lesion assessment in outreach programs. BMC Oral Health 2013;13;2-6.

14. Braga MM, Mendes FM, Gimenez T, Ekstrand KR. O uso do ICDAS para diagnóstico e planejamento do tratamento da doença cárie. PRO-Odonto Prev 2012;5(4);9-55.

15. Santos APP, Marques W, Pentagna MB. Efeitos cariostático e preventivo do diamino fluoreto de prata utilizado em Odontopediatria: uma revisão crítica da literatura. Rev ABO Nac 2008;16(2);98-101.

16. Bijella MFTB, Bijella VT, Silva MSMB, Lopes ES. Avaliação clínica da aplicação de diamino-fluoreto de prata a $12 \%$ (Bioride) na dentição decídua e seu efeito na incidência de cárie em primeiros molares permanentes. Rev Paul Odontol $1991 ; 13(5) ; 28-35$.

17. Andrade KCGE, Maciel SM, Guedes-Pinto AC, Jaeger RG. Reações da dentina cariada humana após aplicação do diamino fluoreto de prata a 10\%: estudo através de microscópio eletrônico de varredura. Rev Bras Odontol 1992;49(8);31-6.

18. Llodra JC, Rodriguez A, Ferrer B, Menardia V, Ramos T, Morato M. Efficacy of silver diamine fluoride for caries reduction in primary teeth and first permanent molars of schoolchildren: 36-month clinical trial. J Dent Res 2005;84(8);720-4

19. Chibinski ACR, Wanbier DS. Avaliação clínica dos níveis salivares de estreptococos mutans na fase preparatória do meio bucal em pré-escolares. Int J Dent 2010;9(2);68-73.

20. May LM, Mei ML, Ito L, Cao Y, Li QL, Lo EC, et al. Inhibitory effect of silver diamine fluoride on dentine demineralisation and collagen degradation. J Dent 2013;41(9);809-17.

21.Wanbier DS, Simionato MRL, Bandeira LR, Adimari LAW. Avaliação de três materiais utilizados na fase preparatória do meio bucal. J Bras Odontopediatr Odontol Bebê 2002;5(25);230-4.

22. Leal SC, Bezerra ACB, Toledo OA. Orientações terapêuticas utilizadas pelos cursos de especialização em odontopediatria no Brasil para cárie severa da infância. ABENO 2004;4(1);5762.

23. Yamaga R, Nishino M, Yoshida S, Yokomizo I. Diamine silver fluoride and its clinical application. J Osaka Univ Dent Sch.1972;12;1-20. 